\title{
Wenchuan Earthquake: Way of thinking is changed
}

\author{
1 China Earthquake Administration, Beijing, China. E-mail: yongchen@seis.ac.cn \\ 2 National Earthquake Infrastructure Service, Beijing, China. \\ 3 Institute of Geology and Geophysics, Chinese Academy of Sciences. \\ 4 China Earthquake Networks Center, China Earthquake Administration, Beijing, China.
}

On 12 May, 2008, at 14:28:04 local time, an $M_{s} 8.0$ earthquake struck the Wenchuan County, Sichuan Province, in southwest China (Figure 1). This quake left about 70,000 people dead, 18,000 missing and over 370,000 injured. In the 75 days after the main shock, 20,000 aftershocks were recorded, which included 241 with $M_{s} \geq 4.0,205$ with $4.0 \leq M_{s} \leq 4.9$, 30 with $5.0 \leq M_{s} \leq 5.9$, and 6 with $M_{s} \geq 6.0$. The largest aftershock took place 13 days after the main shock, in Qingchuan County, 110 $\mathrm{km}$ northeast of the epicenter of the quake (Chen, 2008). The losses from the quaketriggered geological disasters accounted for over a third of the total quake losses, which is extremely rare in the history of earthquake disasters. Secondary disasters, such as landslides, rockslides, landfalls, debris flows, etc., were widely distributed. Large numbers of buildings collapsed, including ones with steel reinforcing in the area of the epicenter. Infrastructure was badly damaged. In many areas, communications, and power and water supplies were cut off. The earthquake left over 35 large quake-dammed lakes, which threatened further disasters in the catchment areas.

The 5.12 quake broke several records in the history of modern China. It was the most devastating quake and had the widest range of destruction. In addition, it involved the greatest rescue efforts. It

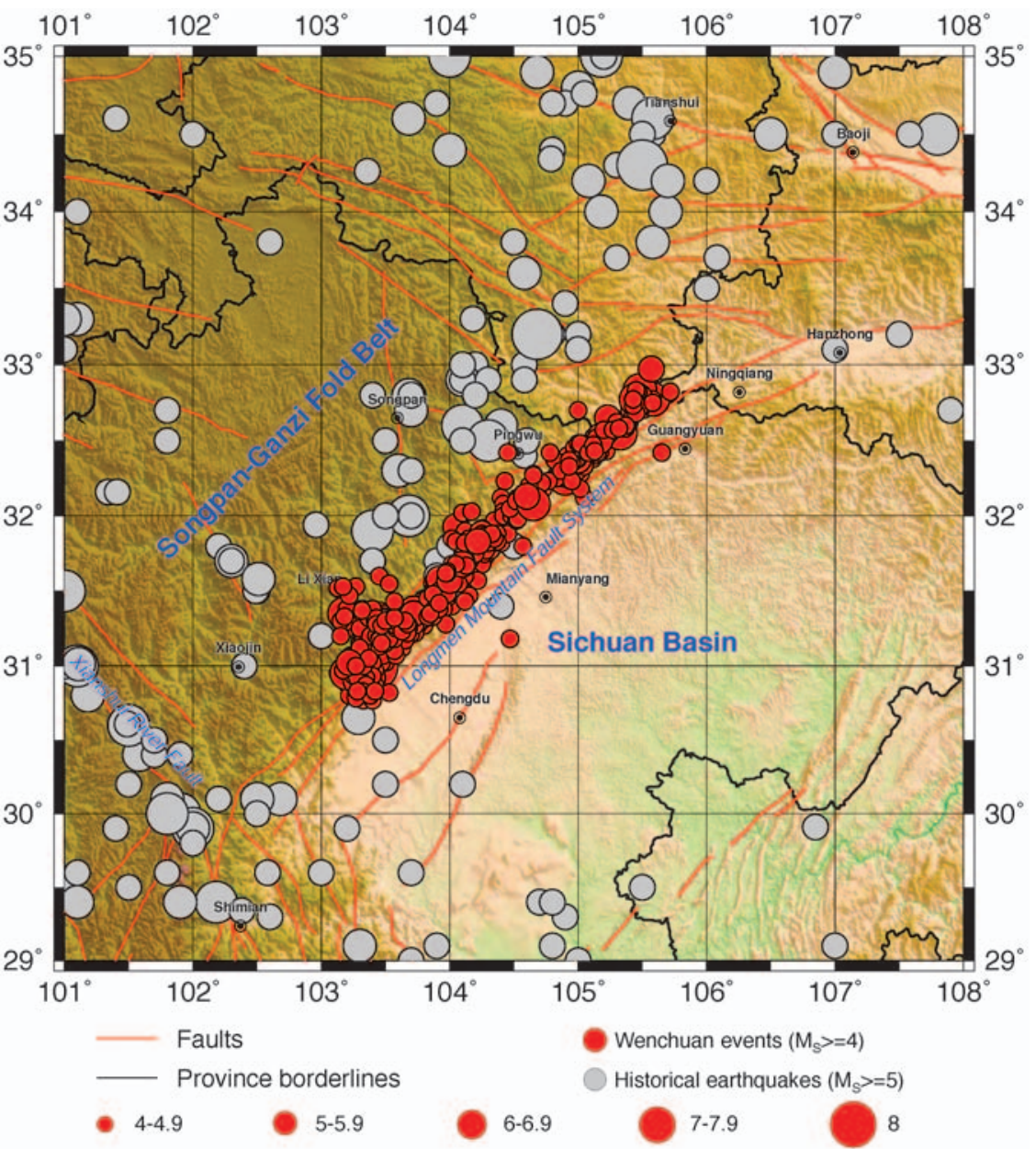

Figure 1 Sketch map for the 5.12 Wenchuan Earthquake with active faults. affected the lives of about 28 million people in an area of over 130,000 $\mathrm{km}^{2}$, caused severe damage to about a million urban and four million rural buildings, and left some 10 million people homeless. Preliminary estimates show that the total economic losses topped 10 trillion $R M B$, which is equivalent to the 2007 GDP of Sichuan Province and 1.6 times higher than that caused by the Hanshin Earthquake in Japan in 1995.

The 5.12 quake reminded scientists of the urgency of continuous research to improve earthquake prediction and damage prevention. This article provides geological and geophysical information intended to help scientists to better understand the impacts of this quake and to predict such events in the future.

\section{Modern China's most devastating earthquake}

\section{Shockwaves circled the earth}

The seismic waves generated by the 5.12 Wenchuan Earthquake traveled across the Earth, and the surface waves it generated traveled around the Earth in several circles, as shown in Figure 2. The ground motions were dominated by surface waves (Rayleigh waves), which produced peak-to-peak amplitudes of over $1 \mathrm{~mm}$ (see scale at lower right) everywhere on the Earth's surface. The series of major arrivals at each station involve $R_{1}$ (the Rayleigh waves that travel along the minor great circle arc), $R_{2}$ (Rayleigh waves traveling along the major great circle arc), $R_{3}$ (the same pulse as $R_{1}$, but with 


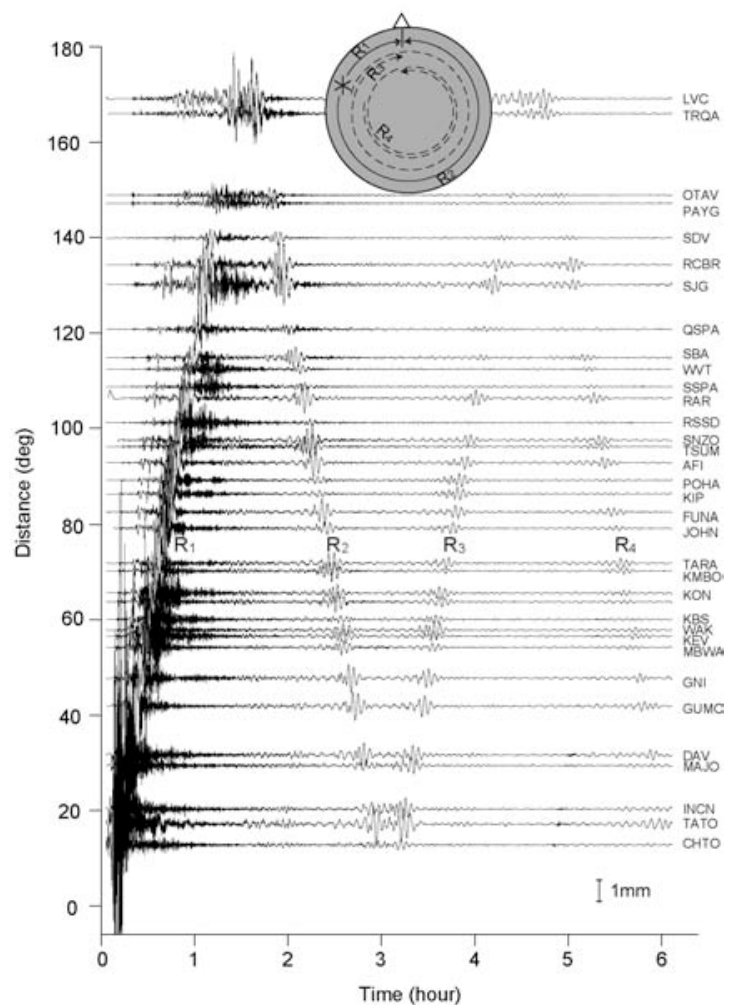

Figure 2 Seismic waves recorded by seismographs over the globe.

an additional transmission round the globe); and $R_{4}$ (the same pulse as $R_{2}$ with an additional global transmission).

The energy released $(E)$ is usually used to define the magnitude $(M)$ of an earthquake, according to the formula $\log E=11.8+1.5 \mathrm{M}$. Therefore, the energy released by the 5.12 Wenchuan Earthquake is calculated as $10^{23.8} \mathrm{erg}$, equivalent to $10,000,000$ tons of TNT, or 1,000 Hiroshima A-bombs.

\section{Seismic waves generated by Wenchuan Earthquake}

The energy of an earthquake spreads rapidly through the globe as seismic waves. The spreading velocities of the different waves vary in different seismic phases while the damage caused on the ground varies according to the different kinds of waves. $P$ waves travel the fastest, and cause the least damage. The surface waves travel more slowly, making the ground shake severely and causing more damage. After the main shock on 12 May, 2008, the $P$ and surface waves took 200 seconds and 300 seconds or more, respectively, to reach Beijing, about 1,530 km away from the epicenter.

Figure 3 shows the Rayleigh waves recorded at the Baijiatuan (BJT) Earthquake Observation Station in Beijing. The dual amplitude of $7 \mathrm{~cm}$ explains why the inhabitants of tall buildings in Beijing felt significant shakings five minutes after the Wenchuan Earthquake.

\section{In people's memory}

The 5.12 Wenchuan Earthquake was a shallow quake located on the inner part of a continental plate, as was the Tangshan Earthquake (28 July, 1976, $M_{\mathrm{s}}$ 7.6). However, in terms of strength, intensity and economic losses, the 5.12 event was substantially more serious than the Tangshan Earthquake. The ground rupture caused by the 5.12 event was around $300 \mathrm{~km}$-three times of that of the Tangshan Earthquake, let alone the former's 120-second duration time of co-seismic slips.

The Grafenberg (GRA1) array in Germany recorded both the 5.12 event and the Tangshan Earthquake. Figure 4 shows the waveforms of the two strong earthquakes that it recorded. The distances

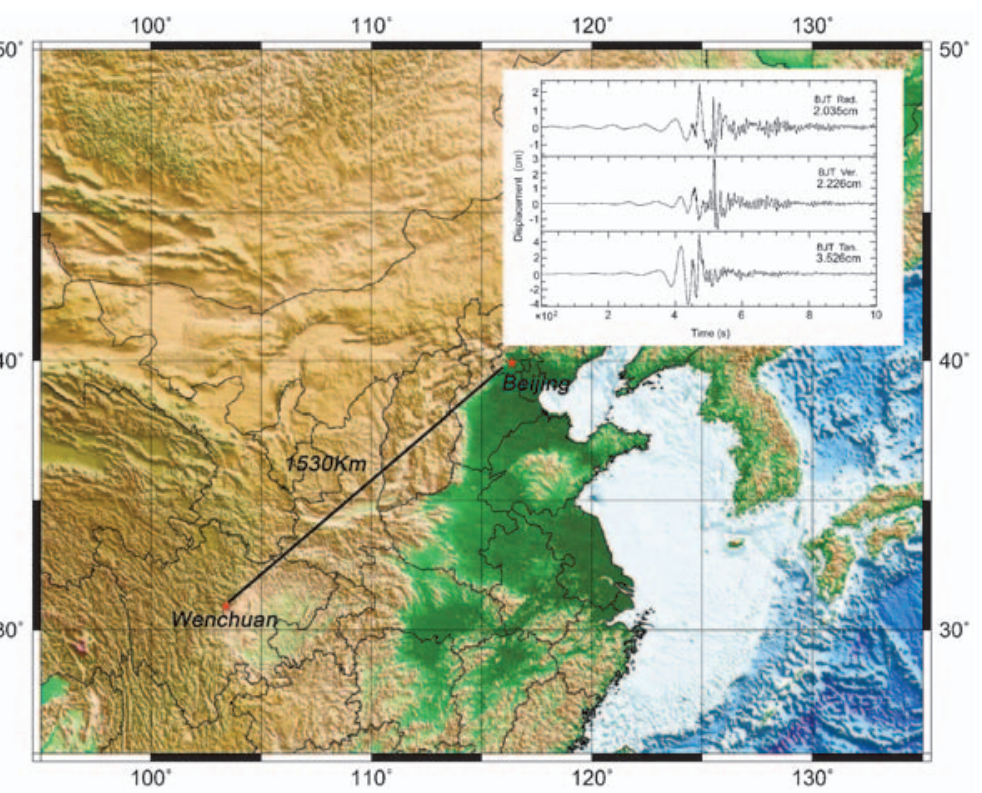

Figure 3 Seismic Rayleigh waves recorded by the BJT station in Beijing. The displacement of the ground at this station is around $7 \mathrm{~cm}$. The main periods of seismic waves are $20 \mathrm{~s}$ and $5 \mathrm{~s}$.

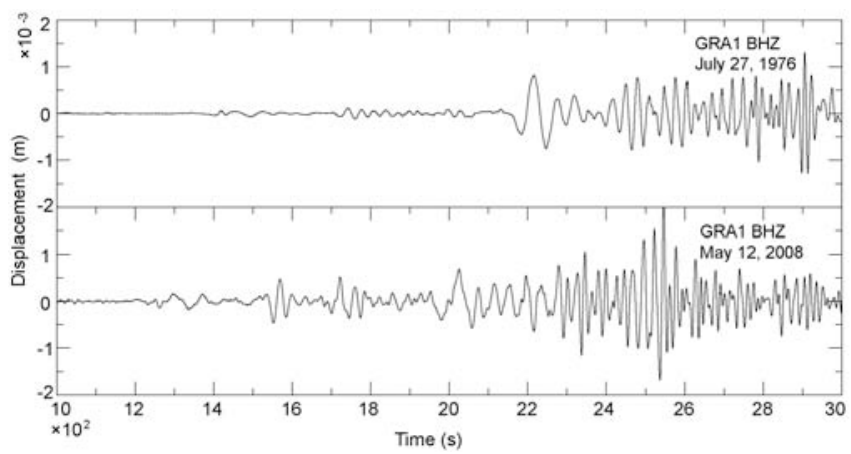

Figure 4 Waveforms of the 5.12 Wenchuan Earthquake and the Tangshan Earthquake of 1976 recorded by the CRA1 station. The maximum amplitude of ground shaking of Wenchuan is about 2 times of that of Tangshan.

from the GRA1 to the epicenter of the Tangshan Earthquake and to that of the Wenchuan Earthquake are about 7,800 km and 7,600 km, respectively. Since the attenuation of the seismic waves of the two events was similar, the amplitude difference of the waves recorded at the station indicates the strength difference of the two events. Figure 4 shows that the Wenchuan Earthquake was stronger than the Tangshan Earthquake.

\section{Thrust system inside a continent}

The 5.12 Wenchuan Earthquake occurred at the Longmen Mountain Fault System (LMFS) with $300 \mathrm{~km}$-long ground-surface ruptures. The LMFS contains a series of faults in a northeasterly direction, which is the bridge between the Tibetan Plateau on its western side and the Yangtze Block on its eastern side (Burchfiel et al., 2008). The high topographical and geophysical gradient belt known as the North-South Seismic Belt, crosses the LMFS, and divides the crust into eastern and western parts. There are high mountains and deep valleys in the LMFS. Within $50 \mathrm{~km}$ from east to west, the average elevation changes sharply from $2.5 \mathrm{~km}$ to $5.5 \mathrm{~km}$, with the highest peak being $7.5 \mathrm{~km}$. Towards the core, the thickness of the crust also changes sharply, from $40 \mathrm{~km}$ to $60 \mathrm{~km}$. 
Table 1 Focal menchanisns of oceanic quakes occurred in the subduction zones (2006-2008, data source: USGS)

\begin{tabular}{c|c|cc|c|c}
\hline Date & Mw & \multicolumn{1}{c|}{ Location } & $\begin{array}{c}\text { eepth } \\
(\mathbf{k m})\end{array}$ & $\begin{array}{c}\text { Type of } \\
\text { fault }\end{array}$ \\
\hline 20080705 & 7.7 & $53.90^{\circ} \mathrm{N}, \quad 153.10^{\circ} \mathrm{E}$, Sea of Okhotsk & 630 & thrust \\
\hline 20080220 & 7.4 & $2.8^{\circ} \mathrm{N}, \quad 96.0^{\circ} \mathrm{E}$, Simeulue, Indonesia & 35 & thrust \\
\hline 20071209 & 7.8 & $26.1^{\circ} \mathrm{S}, \quad 177.3^{\circ} \mathrm{W}$, South of the Fiji Islands & 149.2 & thrust \\
\hline 20071114 & 7.7 & $22.1^{\circ} \mathrm{S}, \quad 69.7^{\circ} \mathrm{W}$, Antofagasta, Chile & 40 & thrust \\
\hline 20070928 & 7.5 & $22.1^{\circ} \mathrm{N}, \quad 142.8^{\circ} \mathrm{E}$, Mariana Islands region & 261.3 & thrust \\
\hline 20070913 & 7.9 & $2.5^{\circ} \mathrm{S}, \quad 100.9^{\circ} \mathrm{E}$, Southern Sumatra, Indonesia & 30 & thrust \\
\hline 20070912 & 8.5 & $4.4^{\circ} \mathrm{S}, \quad 101.5^{\circ} \mathrm{E}$, Southern Sumatra, Indonesia & 34 & thrust \\
\hline 20070816 & 8.0 & $13.3^{\circ} \mathrm{S}, \quad 76.5^{\circ} \mathrm{W}$, Coast of Central Peru & 39 & thrust \\
\hline 20070809 & 7.5 & $6.1^{\circ} \mathrm{S}, \quad 107.7^{\circ} \mathrm{E}$, Java, Indonesia & 289.2 & thrust \\
\hline 20070402 & 8.1 & $8.5^{\circ} \mathrm{S}, \quad 156.7^{\circ} \mathrm{E}$, Solomon Islands & 10 & thrust \\
\hline 20070121 & 7.5 & $1.2^{\circ} \mathrm{N}, \quad 26.5^{\circ} \mathrm{E}$, Molucca Sea & 10 & thrust \\
\hline 20070113 & 8.1 & $46.4^{\circ} \mathrm{N}, \quad 154.3^{\circ} \mathrm{E}$, East of the Kuril Islands \\
\hline 20061115 & 8.3 & $46.6^{\circ} \mathrm{N}, \quad 153.3^{\circ} \mathrm{E}$, Kuril Islands & 30.3 & thrust \\
\hline 20060717 & 7.7 & $9.4^{\circ} \mathrm{S}, \quad 107.4^{\circ} \mathrm{E}$, South of Java, Indonesia & 34 & thrust \\
\hline 20060503 & 8.0 & $20.0^{\circ} \mathrm{N}, \quad 174.2^{\circ} \mathrm{W}$, Tonga & 55 & thrust \\
\hline 20060421 & 7.6 & $61.0^{\circ} \mathrm{N}, \quad 167.2^{\circ} \mathrm{E}$, Koryakia, Russia & 22 & thrust \\
\hline
\end{tabular}

Table 2 Focal mechanisms of continental earthquake (1999-2008, data source: USGS)

\begin{tabular}{c|c|c|c|c}
\hline Date & Mw & \multicolumn{1}{c|}{ Location } & $\begin{array}{c}\text { Depth } \\
(\mathbf{k m})\end{array}$ & $\begin{array}{c}\text { Type of } \\
\text { fault }\end{array}$ \\
\hline 2008.05 .12 & 7.9 & $30.95^{\circ} \mathrm{N}, 103.40^{\circ} \mathrm{E}$, Wenchuan, China & 16 & thrust \\
\hline 2003.09 .27 & 7.3 & $49.9^{\circ} \mathrm{N}, \quad 87.9^{\circ} \mathrm{E}$, Southwestern Siberia, Russia & 18 & strike-slip \\
\hline 2002.11 .04 & 7.8 & $36.2^{\circ} \mathrm{N}, \quad 90.9^{\circ} \mathrm{E}$, West of Kunlun Shan, China & 15 & strike-slip \\
\hline 2001.01 .26 & 7.8 & $23.2^{\circ} \mathrm{N}, \quad 70.0^{\circ} \mathrm{E}$, Gujarat, India & 16 & thrust \\
\hline 2000.06 .18 & 7.9 & $13.8^{\circ} \mathrm{S}, \quad 97.3^{\circ} \mathrm{E}$, South Indian Ocean & 15 & strike-slip \\
\hline 1999.08 .17 & 7.6 & $40.2^{\circ} \mathrm{N}, \quad 29.5^{\circ} \mathrm{E}$, Izmit, Turkey & 17 & strike-slip \\
\hline
\end{tabular}

The Wenchuan Earthquake occurred in a thrust system, which is rare for a continent. Thrusts commonly occur in oceanic subduction zones. There are frequent quakes within oceanic plates, especially in subduction zones but the oceanic quakes usually occur much deeper, in association with thrusts. Table 1 shows the mechanisms of great oceanic quakes in the past two years. It can be seen from the table that all the oceanic earthquakes $\left(M_{w}>7.4\right)$ had thrust movements.

The plane of movement of a strike-slip fault is approximately vertical and the rock on opposite sides of the fracture moves horizontally. A thrust is a low-angled fault in which rock on one side of the fault slides up and over the rock on the other side.

Different from oceanic quakes, most continental quakes have strike-slip movements. Table 2 lists all the continental earthquakes with magnitude $M_{w}>7.3$ in the past ten years. The data show that most continental quakes occur at depths of $15 \mathrm{~km}$ to $18 \mathrm{~km}$, with mostly strike-slip faulting, except for the Gujarat Earthquake and the Wenchuan Earthquake.

The Wenchuan Earthquake is very important because it is rare to see this type of event occur on a thrust fault in a continent's interior. More efforts should be put into the study of the two thrust-fault earthquakes, which could provide a better understanding of continental dynamics.

\section{GPS readings blinded researchers to the real threat}

Extended observation data from the global position system (GPS) shows that rate of movement of the LMFS is about $1.5 \mathrm{~mm} / \mathrm{yr}$, which is much less than the Xianshui River Fault System on its southern side and the East Kunlun Mountain Fault Systems on its northern side. How could such a great earthquake take place in an area like the LMFS, which seems relatively inactive? The contributions due to the 'extreme' topography, weak fault movement, and the collision between the Indian and Eurasian plates to the 5.12 Wenchuan Earthquake remain puzzles for geoscientists (Stone, 2008).

Seismic activity at the LMFS had been relatively weak for a long time, with no earthquake magnitude over 7.0 having been recorded. At the southern part of the LMFS, only four earthquakes with magnitudes of $6.0 \leq M_{s} \leq 6.9$ were recorded between January 1970 and March 2008. Two significant events of $M_{\mathrm{s}} 5.0$ were recorded in 1999 . At the north- ern part of the LMFS, no quake with a magnitude over 6.0 was recorded during the same period, as shown in Figure 1.

At the north and west of the LMFS, three earthquakes with $M_{s} \geq 7.0$ occurred in the twentieth century, including the Songpan-Pingwu Earthquakes (16 August, 23 August, 1976, $\left.\mathrm{M}_{\mathrm{s}} 7.2\right)$ and the Diexi Earthquake (25 August, 1933, $\mathrm{M}_{\mathrm{S}} 7.5$ ), which blocked the Minjiang River into several dammed lakes. Some forty-five days after the main shock the banks of the lakes collapsed, and flooded the counties and cities along the river.

The overall earthquake activity of the mainland of China seemed quiet before the 5.12 Wenchuan Earthquake. From 1950 to 2006, the number of $M_{s} \geq 5.0$ earthquakes in mainland China was around fifteen per year, but only six $M_{s} \geq 5.0$ earthquakes occurred in 2007. From the $\mathrm{M}_{\mathrm{s}} 5.7$ event in the Xinjiang Urgur Autonomous Region on 20 July, 2007 until the 5.12 Wenchuan Earthquake, there was not a single $\mathrm{M}_{\mathrm{s}} \geq 5.0$ event in mainland China, and the 153-day-long 'quiescence' turned out to be the fourth quietest period for earthquakes since 1950 . Thus the 5.12 Wenchuan Earthquake took place in a 'quiet' area during a 'quiet' period.

\section{Earthquake predication: The known unknown}

Earthquakes usually take place in clusters, with limited time duration and within a limited region. In the series, the biggest one is regarded as the main shock, and the lesser events after and before the main shock are called aftershocks and foreshocks, respectively. Three days before the Haicheng Earthquake (4 February, 1975, M M $_{\mathrm{s}}$.3), 521 small events were recorded near Haicheng by the analogue seismic observation network in northern China, as shown in Figure 5. Earthquake alerts were publicized, based on the foreshocks.

Unfortunately, no such significant small earthquake activity was observed before the Tangshan Earthquake in 1976 or the Wenchuan Earthquake in 2008, and the total number of deaths in these two earthquakes topped 300,000 . Statistically, only $10 \%$ of earthquakes are detected by their foreshocks and it is very difficult to determine whether a series of shocks in a limited area and with a lim-
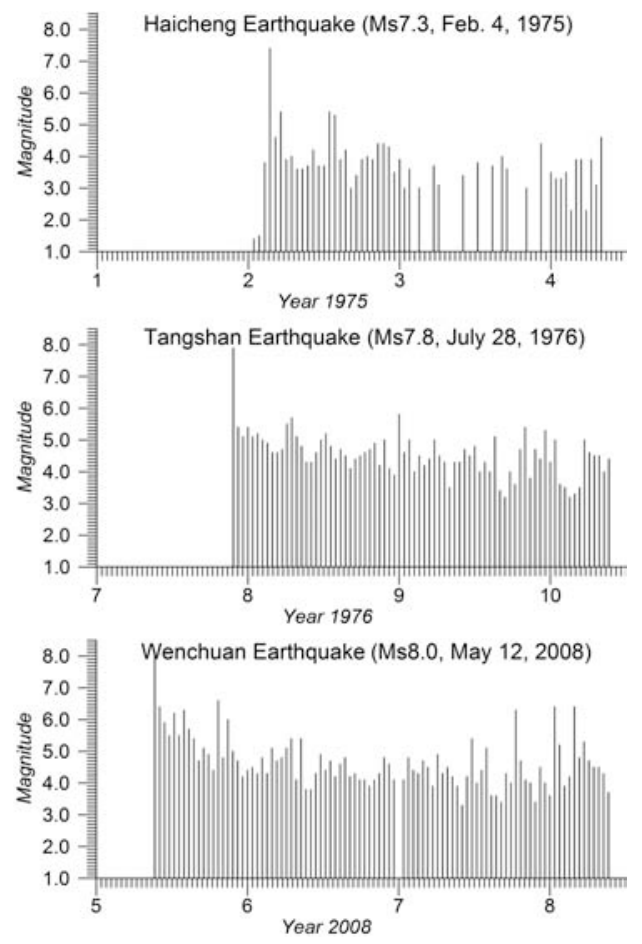

Figure 5 Magnitude-time charts for the Haicheng Earthquake, the Tangshan Earthquake and the Wenchuan Earthquake. 


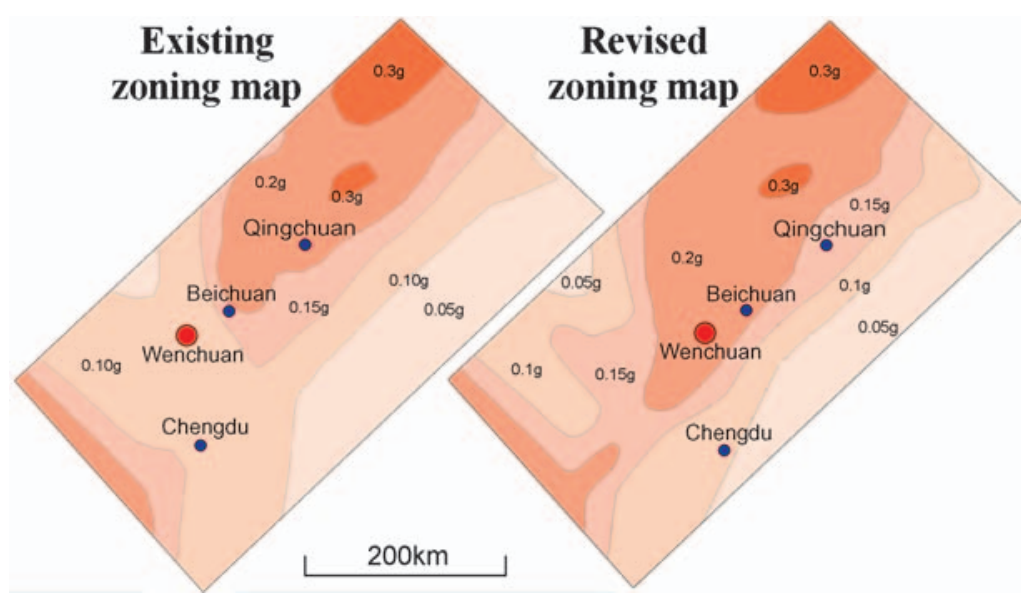

Figure 6 Changes of the seismic zonation map after the Wenchuan earthquake. The left one is taken from the Seismic Ground Motion Parameter Zonation Map of China issued in 2001, and the right one is the revised map issued on 11 June, 2008.

ited duration are foreshocks presaging for a big earthquake or just modest normal fault movements.

Besides abnormal seismicity, other kinds of phenomena have been reported before strong earthquakes, such as significant changes of water level (in wells, etc.), unusual behavior of animals, and unusual cloud formations. Could these earthquake precursors be used to predict or forecast strong earthquakes? In the period 1991-1999, IASPEI evaluated twenty-six prospective earthquake precursors submitted by researchers worldwide, and rejected all except foreshock. Some submitted precursors had time lags of many years, while others had no clear relationship with the subsequent events (Chen, 2007; Wyss, 1991; Wyss, 1997).

Many scientists in other countries concentrate on earthquake research instead of earthquake prediction, due to the difficulties of the latter. However, in China the opposite is the case. Prediction of the Haicheng Earthquake meant that only 1,328 persons losing their lives, while 20,000 lives were saved. On the other hand, only more than 500 persons were saved after the Wenchuan Earthquake, whereas 80,000 lives were lost. At the same time, earthquake hazard prevention has been enhanced in China because of the limitations of earthquake prediction and prompt rescue efforts after the occurrence of earthquakes. A new concept of hazard management-'comprehensive hazard mitigation' - has been adopted by the Chinese Government, which insists that the construction standards of buildings, the establishment of early warning systems, the broadcasting of earthquake information to the public, and regular rescue and evacuation drills be stepped up to mitigate earthquake damage.

\section{Revised seismic intensity map}

In China, the most recent seismic zonation map was issued in 2001. The seismic ground motion parameters in Wenchuan and its surrounding areas (Figure 6, left) changed significantly after the 5.12 quake. From Wenchuan northeast to Beichuan and Qingchuan, a distance of $300 \mathrm{~km}$, severe damage was inflicted, with seismic intensity of IX or more. Most researchers believed that Wenchuan was in a relatively weak earthquake zone, but they are now reconsidering their understanding of the LMFS.

According to the latest data, especially the probability of large earthquake calculation, scientists are now revising their seismic intensity maps. Gao et al. (2008) have completed a new intensity map of LMFS since the Wenchuan Earthquake. They separate the LMFS into three sections: South, Central and North. The southern section is $150 \mathrm{~km}$ long, with an estimated maximum possible earthquake magnitude of $M_{\mathrm{s}}$ 7.5. The central section (where Wenchuan is located) is $220 \mathrm{~km}$ long, with a maximum possible earthquake magnitude of $\mathrm{M}_{\mathrm{s}}$ 8.0. There is limited data at this time about the northern section, but it is believed that the maximum possible earthquake magnitude there is $\mathrm{M}_{\mathrm{s}}$ 7.0.

Based on this new information, we have revised the seismic intensity map for Wenchuan and its surrounding areas, as shown in Figure 6, bottom right. By comparing the newer and older versions, it may be noticed that the revised version is about one degree of intensity higher than the previous one. The revision of seismic intensity maps is an urgent task for planners as regards safe areas for reconstruction, and for drawing up building codes and structural designs. Meanwhile, researchers will continue to revise other parts of the seismic intensity map of China.

The Wenchuan Earthquake was a terrible experience, which China and the rest of the world will remember and study. Although there are still many unanswered questions, by analyzing the Wenchuan events researchers can get a step closer towards reducing the losses due to future natural disasters.

\section{Acknowledgement}

The project is funded by $40730318 \#$ project from National Natural Science Foundation of China.

\section{References}

Chen, Y., 2008, Wenchuan great earthquake in the eyes of earthquake researcher: Science and Technology Review, 26(10), p.3.

Burchfiel, B.C., Royden, L.H., van der Hilst, R.D, Hager, B.H., 2008, A geological and geophysical context for the Wenchuan Earthquake of 12 May 2008, Sichuan, People's Republic of China: GSA Today, 18(7), pp.4-11.

Stone, R., 2008, An unpredictably violent fault: Science, 320, pp.1578-1580.

Chen, Y.T., 2007, Earthquake prediction-progress, difficulties and prospect: Seismological and Geomagnetic Observation and Research, 28(2), pp.1-24.

Wyss. M., 1991, Evaluation of proposed earthquake precursors: American Geophysical Union-Washington D C. 94 pp.

Wyss. M., 1997, Second round of earthquake of proposed earthquake precursors: Pure and Applied Geophysics, 149, pp.3-16.

Gao, M.T., Chen, G.X., Xie, F.R., Yu, Y.X, Zhou, B.G., Pan, H., Ran, Y.K., Zhao, F.X., Lv, Y.J., Xu, G.Y., Wang, J., 2008, Seismic zoning map in part of Sichuan, Gansu and Shaanxi Provinces, Recent developments in world seismology, 6, 9-12.

Yong Chen, graduated in 1965 from the Department of Geophysics, China University of Science and Technology, is Academician of the Chinese Academy of Sciences, Fellow of the Third World Academy of Sciences, and Professor of China Earthquake Administration. His interest is mainly in earthquake hazard mitigation.

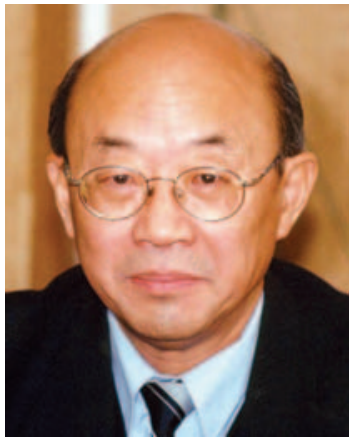

